\title{
ECHINOCHASMUS SWABIENSIS N. SP. (DIGENEA: ECHINOSTOMATIDAE) FROM BLACK KITE (MILVUS MIGRANS MIGRANS) IN SWABI DISTRICT, PAKISTAN
}

\author{
Suleman, S. ${ }^{1}$, Khan, M. S. ${ }^{2}$, Zhu, X. Q. ${ }^{3}$, Dharejo, A. M. ${ }^{4}$ \\ Uwalaka, E. C. ${ }^{5}$, Shah, M. ${ }^{6}$, Adediran, O. A. ${ }^{7}$ \\ ${ }^{1}$ Department of Zoology, Hazara University, Mansehra \\ ${ }^{2}$ Department of Zoology, University of Swabi, Khyber Pakhtunkhwa \\ Pakistan \\ ${ }^{3}$ Lanzhou Veterinary Research Institute, Chinese Academy of Agricultural Sciences \\ Lanzhou, Gansu Province 730046 \\ China \\ ${ }^{4}$ Department of Zoology, University of Sindh, Jamshoro \\ Pakistan \\ ${ }^{5}$ Department of Veterinary Parasitology and Entomology \\ Micheal Okpara University of Agriculture, Umudike \\ Nigeria \\ ${ }^{6}$ Center for Animal Sciences and Fisheries, University of Swat \\ Pakistan \\ ${ }^{7}$ Department of Veterinary Parasitology, University of Ibadan
} Nigeria

emmauwalaka@gmail.com

\section{ABSTRACT}

A new species of the genus Echinochasmushas been described from the small intestine of the black kite (Milvus m.migrans) collected from Swabi, Khyber Pakhtunkhwa, Pakistan and identified as E.swabiensis n. sp. The new species is different from its congeners in its body size; it has 22 collar spines which includes two corner spines on one side, four on the other side and eight marginal plus ventral spines on each side. There aretegumental-scale like spines interspersed on the anterior margin of the ventral sucker with a smaller, terminal oral sucker. The pharynx is nearly twice as large as the oral sucker, while the ventral sucker is nearly six times as large as the oral sucker. The suckers' width ratio is $1: 4.7$ to $1: 5.6$. The vitelline follicles are compact and denser at the lateral sides masking the caeca. This species has been added to the record of trematodes circulating among avian species, especially in the study area.

Key words: Digenea; Echinochasmus swabiensis; fluke; Milvus migrans; Pakistan; Swabi

\section{INTRODUCTION}

The family Echinostomatidae is the largest family of parasitic trematodes, parasitizing birds and mammals in- 
cluding man $[2,5,12,15,19,21,22,23]$. They are characterized by having a head collar with spines and their cercaria encyst in invertebrates like mollusks, insect larvae, freshwater snails, crustaceans, and the gills of tadpoles and fishes $[6,9,18,24,25]$. Echinochasminae is one of ten subfamilies of the family Echinostomatidae distinguished by having a well-developed head collar with interrupted spines arranged in either a single row or sometimes in a double row $[4,21,25]$.

The genus Echinochasmus Dietz, 1909, is characterized by a well-developed head collar bearing $20-24$ or $30-$ 34 spines with the teguments covered by scale like spines, long pre-pharynx, large pharynx, dextral ovary, vitelline field confluent in post-testicular region, a cirrus pouch lying anterior to the ventral sucker or overlapping it, and a uterus which is short with few large eggs when gravid [11,25].

Species of the genus Echinochasmus Dietz, 1909 are cosmopolitan in distribution and parasitize birds and mammals [11, 12, 17, 21, 25]. Different authors have reported different species of the genus Echinochasmus from various avian hosts $[10,13,16,20]$. Different reports also exist in Pakistan $[1,3,7,8,23]$. This study is aimed at investigating the presence of flukes in the small intestine of the black kite and describes their morphological characterization. This study is the latest addition to the genus Echinochasmus recovered from the black kite.

\section{MATERIALS AND METHODS}

Twelve apparently healthy, adult Black kites (Milvus m. migrans, Boddaert) were trapped alive (July 2012 to March 2014) from various localities of Swabi (34 $7^{\circ} 48^{\prime \prime} \mathrm{N}$ and $72^{\circ} 28^{\prime} 11^{\prime \prime} \mathrm{E}$ ), Khyber Pakhtunkhwa, Pakistan and brought to the laboratory of parasitology at Hazara University, Mansehra, Pakistan. These birds were anesthetized and necropsied for the presence of trematode parasites. The entire digestive system with other visceral organs including lungs, liver and heart were removed and placed in separate petri-dishes containing physiological saline. These organs were examined with the aid of a dissection microscope. Four specimens were found in the contents of the intestine of a single bird. The flukes were removed, placed in saline solution until dead and then fixed in AFA solution (70\% ethanol, $92 \mathrm{ml}$; formaldehyde, $6 \mathrm{ml}$; and acetic acid, $2 \mathrm{ml}$ ) under tolerable pressure of glass slides. They were then stained in Mayer's carmalum, dehydrated in graduated series of ethanol (70-100\%), clarified in xylene and mounted permanently in Canada balsam for further study. Line drawings were prepared with the aid of a drawing tube and photomicrographs were taken by using an Olympus DP12 camera. All measurements were given in millimetres. By using trematodes identification keys and the available literature $[11,12,22,25]$ the recovered specimens were placed in the genus Echinochasmus Dietz, 1909. Holotype specimens were deposited in the Laboratory of Parasitology, at Hazara University, Mansehra, Pakistan.

\section{RESULTS}

Table 1. Taxonomic summary

\begin{tabular}{ll}
\hline Subfamily & Echinochasminae (Odhner, 1910) \\
\hline $\begin{array}{l}\text { Species } \\
\text { Host }\end{array}$ & $\begin{array}{l}\text { Echinochasmus swabiensis n.sp } \\
\text { Black kite (Milvus m. migrans, Boddaert) } \\
\text { collection }\end{array}$ \\
$\begin{array}{l}\text { Locality type } \\
\text { Number of specimen }\end{array}$ & Yar Hussain, Swabi \\
$\begin{array}{l}\text { Frequency } \\
\text { of appearance }\end{array}$ & $8.33 \%$ \\
$\begin{array}{l}\text { Accession number host, 12 samples examined } \\
\end{array}$ & HUPE-1 \\
\hline
\end{tabular}

The morphology of Echinochasmus swabiensis n. sp. was based on four specimens of these trematodes. The more clear permanently mounted slides were used for the morphological studies. The head end of these specimens presented the characteristic features of the genus Echinochasmus Dietz, 1909, with a small, triangular mouth opening and reniform head collar bearing 22 large spines in a single dorsally interrupted row (Figs. $1 \mathrm{~b}$ and 1d).

The worms were small, thin, elongated, with a gradually tapering anterior end and somewhat broadly rounded posterior end. The total body length was $2.85-2.95 \mathrm{~mm}$ with a maximum width of $0.525-0.575 \mathrm{~mm}$, at the region of acetabulum or its posterior border (Fig. 2a). The anterior body was $0.95-0.1 \mathrm{~mm}$ long while the posterior body was $1.9-1.95 \mathrm{~mm}$ long, so that the anterior body and posterior body length ratio was $1: 2$. The tegument was covered by scale like spines, interspersed only up to the region of the ventral sucker. 
The oral sucker was terminal, slightly protruding and much smaller than the pharynx (Fig. 2a), measured $0.058-0.063 \times 0.075-0.08 \mathrm{~mm}$ in size; nearly half of the size of the pharynx (Fig 2a). The head collar was $0.13-$ $0.20 \times 0.29-0.3 \mathrm{~mm}$ in size, bearing 2 corner spines on one side, while 4 on the other side with 8 marginal plus ventral spines on each side; so that one side consisted of 12 spines, while the other had 10 spines (Fig. 2b). The collar spines were $0.047-0.06 \times 0.018-0.022 \mathrm{~mm}$ in size. The corner spines were smaller, $0.028-0.03 \times 0.013-0.02 \mathrm{~mm}$ in size, while the marginal and ventral spines were $0.04-0.075 \times$ $0.02-0.023 \mathrm{~mm}$ and $0.073-0.075 \times 0.022-0.023 \mathrm{~mm}$ in size, respectively (Fig. 2d).

The pre-pharynx was present but varied in length from 0.05 to $0.063 \mathrm{~mm}$, due to the contraction of the neck of the flukes (Fig. 2a). The pharynx was nearly twice as large as the oral sucker (Fig. 2a), globular to nearly oval, measured
$0.13-0.134 \times 0.13-0.15 \mathrm{~mm}$ in size, followed by 0.33 to $0.5 \mathrm{~mm}$ long esophagus which was divided into two intestinal caeca at a distance of $0.45-0.59 \mathrm{~mm}$ from the anterior end of the body. The intestinal bifurcation occurred a short distance ahead of the ventral sucker and the intestinal caeca were masked by the lateral fields of the vitellaria (Fig. 2c). The ventral sucker was six times larger in length than the oral sucker, rounded to oval with well-developed muscular walls, $0.35-0.38 \times 0.35-0.45 \mathrm{~mm}$ in size and was situated in the second quarter of the body at a distance of 0.65 to $0.83 \mathrm{~mm}$ from the anterior end of the body. The width of the suckers had a ratio of $1: 4.7$ to $1: 5.6$.

The two testes were with entire margins, post-equatorial, median, lying one behind the other, contiguous and separated by a smaller gap and were sub-equal in size. The anterior testis was transversely elongated, somewhat rectangular, $0.11-0.25 \times 0.26-0.35 \mathrm{~mm}$ in size and was situat-

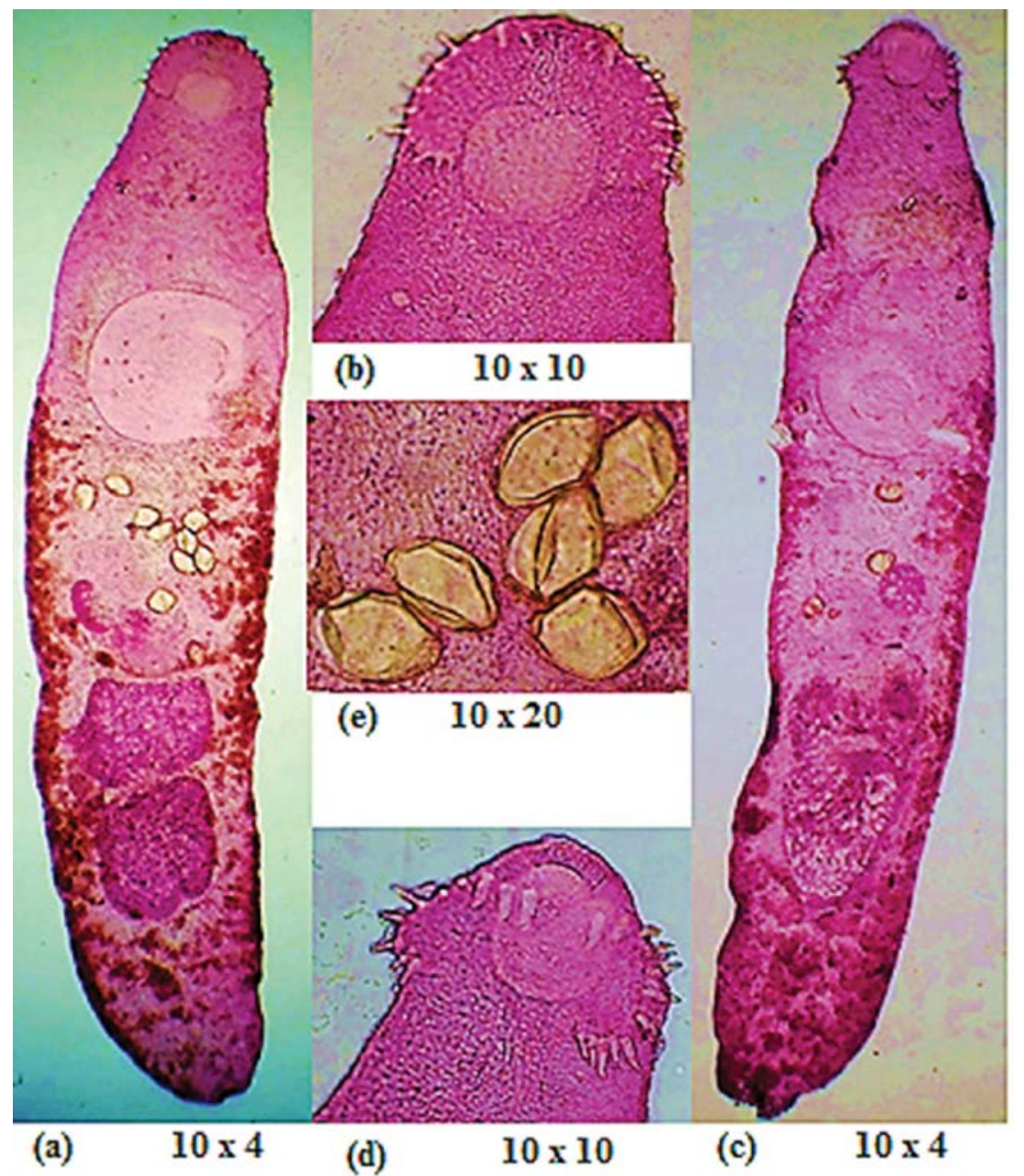

Fig. 1. Photomicrographs of Echinochasmus swabiensis $\boldsymbol{n}$. sp. and (c) - entire specimens; (b) and (d) - head collars; (e) - eggs 


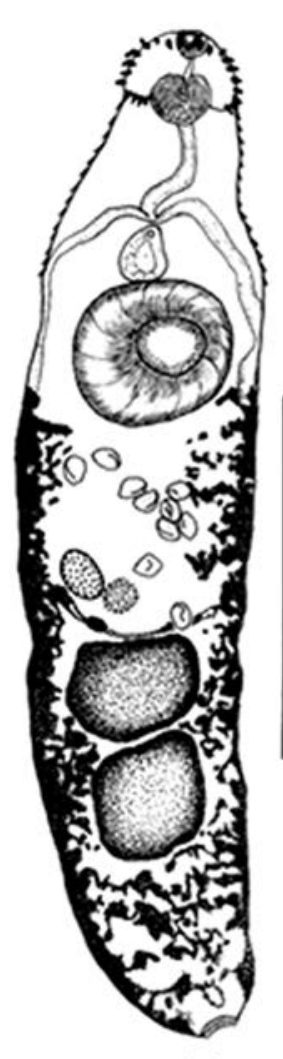

(a)

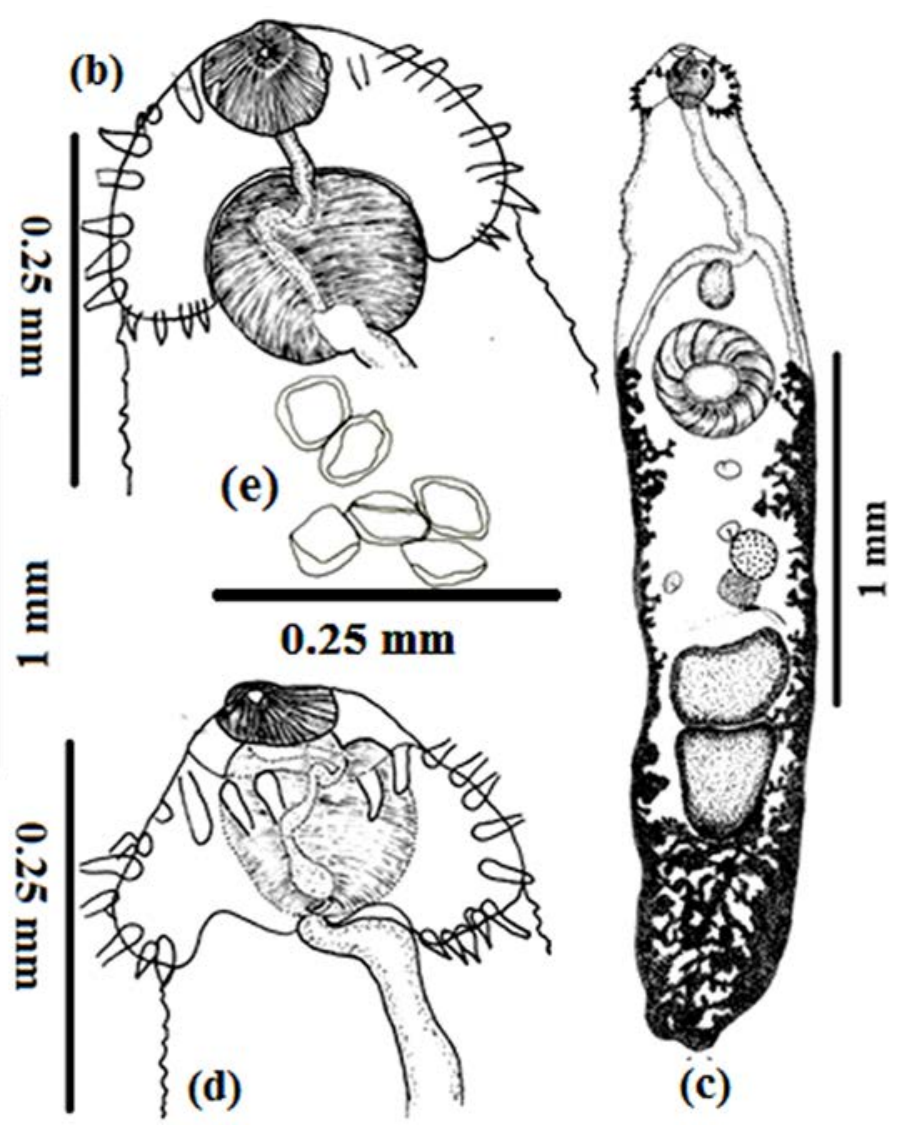

Fig. 2. Diagrams of Echinochasmus swabiensis $n$. sp. and (c) - whole specimens; (b) and (d) - head collars;(e) - eggs

ed at a distance of 0.6 to $0.65 \mathrm{~mm}$ from the posterior border of the ventral sucker (Fig. 2a and 2c). The posterior testis was longer than wide, quadrilateral or nearly triangular with tapered posterior end and measured $0.325-0.372 \times$ $0.3-0.322 \mathrm{~mm}$ in size. The distance between the posterior border of the posterior testis and the posterior end of the body was 0.47 to $0.575 \mathrm{~mm}$. The vasa efferentia were inconspicuous. The cirrus pouch was small, nearly oval, $0.15-$ $0.164 \times 0.1-0.13 \mathrm{~mm}$ in size and was situated between the intestinal bifurcation and ventral sucker or overlapping the anterior border of the ventral sucker. The cirrus was inconspicuous and the genital pore laid between the intestinal bifurcation and the ventral sucker (Fig. 2c).

The ovary was rounded to oval in shape, equatorial or post-equatorial and laid slightly at one side of the body; 0.28 to $0.3 \mathrm{~mm}$ away from the posterior border of the ventral sucker (Fig. 2a). It was much smaller than the testes and measured $0.145-0.15 \times 0.1-0.125 \mathrm{~mm}$ in size. The shell gland was smaller than the ovary, sub-median, situated in the close proximity of the ovary. The vitelline reservoir with transverse vitelline ducts was situated posterior to the shell gland and anterior to the anterior testis. The vitellaria consisted of small follicles which were compact and denser at the lateral sides, masking the caeca. The vitelline folds commencing from about the mid portion of the ventral sucker or its posterior border, ran laterally and met freely behind the posterior testis. The uterus consisted of a few folds containing few, yellowish, large eggs, $0.058-0.078 \times 0.046-$ $0.06 \mathrm{~mm}$ in size (Fig. 1a and 2a). The excretory bladder had a chamber like appearance and opened into the terminal or sub-terminal excretory pore (Fig. 2c).

\section{DISCUSSION}

The genus Echinochasmus was proposed by Dietz, 1909 with the type species E.coaxatus, in Europe, Central Asia, Siberia $[25,11]$.

Our studied species is larger in size $(2.85-2.95 \times$ 0.525-0.575) than E. liliputanus (Looss, 1896) Odh- 
ner, $1910(0.5-0.8 \times 0.2)$, E.japonicas Tanabe, 1926 (0.6-0.9 $\times 0.16-0.18)$, E.microacetabulum Leonov, 1958 (0.702-0.936×0.28-0.34), E. milvi Yamaguti, 1939 (0.7-1.2×0.27-0.32), E.zubedakhaname Nasir, Dietz, 1968 (0.850-1.675 ×0.225-0.555), E.donaldsoni Beaver, $1941(0.88-1.84 \times 0.256-0.32)$, E. dietzevi Issaitschikoff, $1927(1.13-1.47 \times 0.39-0.55)$, E.bagulai Verma, $1935(1.0-1.75 \times 0.25-0.5)$, E. megavitellus Lal, $1939(1.05 \times 0.45)$, E.haliasturis Odening, 1962 (1.1-1.9 $\times 0.8-0.9)$, E. vindhianae Vasudev, 1973 (1.82$1.92 \times 0.38-0.45)$, E. spinosus (Odhner, 1910) Skrjabin, Bashkirova, $1956(2.02-2.25 \times 0.4-0.5)$, E. coaxatus Dietz, $1909(2.13-2.56 \times 0.65-0.81)$ and E. spinulosus $\mathrm{Ru}$ dolphi, $1809(1.09-2.7 \times 0.41-0.43)$. It is however smaller in size than E.euryporus Looss, 1896 (3-4×0.85), E. novalichesensis Tubangui, $1932(2.32-3.25 \times 0.48-0.75)$, E. botauri Baer, 1923 (3.25×0.65), E. amphiboles Kotlan, $1922(4.16-5.16 \times 0.765)$, E.tobi $(6.5-7.5 \times 1.1-1.3)$, E. fanielicus (Odhner, 1910), Prudhoe, $1944(8.65 \times 1.55)$ and E.antigonus Gupta, 1955 (11.75-12.92×1.2-1.43).

Our studied species is also bigger in size than the species recovered from other avian hosts in Pakistan. These species include E.jamshorensi $(0.432 \times 0.124)$, E. mohiuddini $(0.780-1.613 \times 0.215-0.416)$, E.passeri $(0.725 \times 0.285)$ and E.mazharuddini $(0.81-0.88 \times 0.39-0.42)$ described by $[3,7,8]$ and $[23]$, respectively.

Using the number of spines as morphological characteristics, our studied species has a resemblance with E.cohensi Rao, 1951, E.euryporus, E.gorsakii, 1939, E.microacetabulum, E. milvi, E.mordax (Looss, 1899), Price, 1931, E.muraschkinzewi Bashkirova, 1941, E.spinosus, E.spinulosus, E.vindhianae, in having 22 spines; while it differs from E.accipiteri Bhutta, Khan, 1975, E.japonicus, E. botauri, E. beleocephalus, E.bagulai, E.novalichesensis, E.megavitellus, E.oligolecithosus Mendheim, 1940, E. tobi, E.militaris Leonov, 1958, E. liliputanus, E.coaxatus, E.famelicus (Odhner, 1910), Prudhoe 1944, E.amphibolus, E.ruficapensis, E.perfoliatus Ratz, 1908, E.africanum Stiles, 1901, E.jamshorensi, E.mohiuddini which has 24 spines; E. zubedakhaname, E. donaldsoni, E. dietzevi which has 20 spines; E. passeriwith 26 spines; and E. mazharuddini with 28 spines.

The eggs of our specimen under study $(58-78 \times 46-60$ $\mu \mathrm{m}$ or $0.058-0.078 \times 0.046-0.06 \mathrm{~mm})$ (Fig. 1e and $2 \mathrm{e}$ ) are larger in size than those of E. zubedakhaname $(42-67 \times 32-$ $40)$ and E.euryporus $(67 \times 42)$; while they are smaller than the eggs of E.gorsakii $(72-90 \times 51-57)$, E. oligolecithosus (73-83×54-76), E.milvi $(78-84 \times 51-57)$, E. botauri (84-97×46-65), E.colymbi Shigin in Skrjabin, Bashkirova, $1956(87 \times 60)$, E.novalichesensis (95.6$108 \times 58.2-70.7)$, E. amphiboles (97.2-102.6 $\times 59.4-67.5)$, E.tobi (102-117 $\times 60-72)$, E. antigonus (104- $126 \times 57-$ $68)$ and E.famelicus (110-120×70-80).

Our studied species' eggs differ from the eggs of E. beleocephalus $(73-81 \times 34-43), \quad$ E.vindhianae $(67 \times 40)$ and E.spinosus $(74-80 \times 40)$ in width and from the eggs of E. muraschkinzewi $(81-96 \times 43-47)$, E. cohensi (84$89 \times 49-52.5)$ and E.mirus Mendheim, 1940 (92$100 \times 4856)$ in length.

The type species, E. coaxatus Dietz, 1909, is sub-equal to our studied species in the size of the pharynx and ovary, resembling it in the extension of the vitellaria but differs in having a maximum width in the region of the testes; 24 larger collar spines $(0.0768-0.0816 \times 0.019-0.0216)$ with 3 corner spines and 9 marginal spines on each side; cuticle spines scattered up to the posterior level of the acetabulum; oral sucker two times as large as the oral sucker of our studied species; smaller ventral sucker; longer prepharynx and esophagus; larger testes lie mid-way between the ventral sucker and rear end of the body. Moreover, the ratio in size of the oral sucker to the acetabulum is about 1:2.6 in E. coaxatus and 1:4.7 to 1:5.6 in our studied species.

E. mordax (Looss, 1899), Price, 1931 resembles this new species in the number of spines; size of oral sucker and eggs, and extension of the vitellaria; but differs in body shape and arrangement of the collar spines (2 corner and 9 marginal spines on each side); having a smaller body with a maximum width at the level of the cirrus sac; smaller pharynx and ventral sucker; tegument spines distributed up to the level of the posterior testis but very dense in between the ventral sucker and head; smaller and globular testes; cirrus sac oval extending dorsally from the intestinal fork to $2 / 3$ of the length of the acetabulum; the size of the ventral sucker is nearly equal to the size of the pharynx of the present studied species.

E.bagulai Verma, 1935, differs in having a smaller body with a maximum width at about the middle of the testes; 24 collar spines with 4 corner spines and 8 marginal spines on each side; the spines on the cuticle extend to the posterior end of the body; the pharynx has the same mean diameter as the oral sucker; the acetabulum is three times as large as the oral sucker and situated at the commence- 
ment of the middle third of the body. The oral sucker is larger, while the pharynx and acetabulum are smaller and have 9 to 15 numbers of eggs.

E. vindhianae Asudev, 1973 collected from an Indian Tawny eagle, Aquila rapaxvindhiana is similar in having 22 collar spines; maximum width at the level of the acetabulum; caeca are masked by the vitelline follicles and the vitelline fields extending anteriorly up to the mid-level of the acetabulum but differs in having 3 corner spines and 8 marginal spines on each side of the head collar; the oral sucker and pharynx are sub-equal in diameter; shorter esophagus; intestinal fork occurs at a distance of $0.37-0.44 \mathrm{~mm}$ from the anterior end of the body; suckers width a ratio of $1: 4.2$; and the testes are oval in shape and situated in the middle of the body.

E. novalichesensis Tubangui, 1932, collected from the small intestine of Hyptaenidiatorquata in Novaliches, Rizal, Luzon, differs in having somewhat larger body with a maximum width across the anterior testis; larger head collar bearing 24 spines with 3 corner spines and 9 marginal spines on each side; tegumental spines distributed up to the level of the anterior testis; suckers width a ratio of $1: 2.7$; much smaller pharynx; oval and elongated cirrus pouch; ovary equatorial or pre-equatorial; shell gland median and larger than ovary.

E.spinulosus Rudolphi, 1809, syn. Monilifer spinulosus Diets, 1910, differs in having a smaller body; 2 corner spines and 9 marginal spines on each side of the head collar; much smaller pharynx (sub-equal to the size of oral sucker); much smaller ventral sucker; suckers with a width ratio of $1: 2.8$ to $1: 3.2$; vitelline fields commencing from the level of the testes and vitelline ducts arise from the anterior end of the vitelline fields; ovary smaller in size and situated just before the anterior testis. Differences are also found in the shape of the testes.

E.macrocaudatus Ditrich et al., 1996, differs in having a smaller body; tegumental spines covered $2 / 3$ of the dorsal surface and ventral surface of the body; smaller collar spines, varies in number, $22(11+11), 23(11+12), 24$ $(12+12)$; larger, sub-terminal oral sucker; a smaller ventral sucker; smaller pharynx; suckers width a ratio of $1: 1.68$; ventral sucker situated at about 2/5 of the body length; prepharynx short or absent; cirrus sac elongated and anterodorsal to the acetabulum with a large seminal vesicle.

Our studied species is closely related with E. schwartzi Price, 1931, in general body shape, extension of the vitel- laria and position of ventral sucker and gonads, but differs in having a smaller body with a maximum width at the region of the anterior testis; smaller $(0.037-0.051 \times 0.011-$ 0.015) 22 collar spines ( 2 corner and 9 marginal on each side), tegumental spines covered the body up to the posterior margin of the posterior testis; sub-terminal, larger oral sucker; cirrus sac piriform, extending to the posterior border of the ventral sucker and smaller ovary. The size ratio of the oral sucker to acetabulum is about 1:2 in E. schwartzi and $1: 4.7$ to $1: 5.6$ in our species.

E. zubedakhaname Nasir, Diaz, 1968, reported by Argumedo, Macedo [14] in 1991 differs in having a smaller body with a maximum width at the level of the testes; tegumental spines covered the body up to the posterior margin of the posterior testis; head collar consists of 20 smaller spines, with 3 corner spines and 7 marginal spines on each side; larger oral sucker, longer esophagus and smaller pharynx; smaller, equatorial ventral sucker; suckers width a ratio of $1: 1.9$ to $1: 2.5$; cirrus sac elongated and situated lateral to the anterior margins of the acetabulum; ovary larger, postero-lateral to the acetabulum; vitelline fields extra-caecal and exceeds the anterior margin of acetabulum.

Our specimen also differs from the species reported from Pakistan in size and shape of the body; number and arrangement of collar spines; distribution of vitellaria; size, shape and position of gonads and other organs.

E. mohiuddini [7] differs in size and shape of the body; number and arrangement of collar spines; size and position of the pharynx; shape, size and position of cirrus sac and shape and size of the testes. E. passeri [8] differs in general body shape; number and arrangement of collar spines; size of oral sucker, pharynx and ventral sucker; sucker width the ratio $(1: 2.06)$; length of pre-pharynx and esophagus; shape, size and position of gonads; extension and distribution of vitellaria. E. mazharuddini [23] differs in having a smaller body with maximum width at the level of the testes; a smaller head collar bearing 28 spines including 4 corner spines; longer pre-pharynx; smaller ventral sucker (twice as large as the oral sucker); larger cirrus sac; larger, pear-shaped ovary, overlapped with the acetabulum and anterior testis; smaller testes; extension and distribution of the vitellaira. Moreover, the post-testicular space is $0.122-$ $0.139 \mathrm{~mm}$ long in E. mazharuddini while 0.47 to $0.575 \mathrm{~mm}$ long in our species. E. jamshorensi [3] differs in having a smaller body; smaller head collar bearing 24 spines; larger 
oral sucker; smaller pharynx; much smaller ventral sucker; smaller cirrus sac; smaller gonads and longer post-testicular space.

\section{CONCLUSIONS}

The variations in our studied specimens from the previously described species of the genus Echinochasmus, strengthen the statement that the specimens discovered in our investigation are new to science. This also calls for more research into this particular family especially in the area of its systematics and epidemiology. The new species is named as Echinochasmus swabiensis.

Etymology: Name of new species refers to the locality of the host.

"Nomenclatural acts": This work and the nomenclatural acts it contains have been registered in the Zoo Bank. The Zoo Bank Life Science Identifier (LSID) for this publication is:LSIDurn:lsid:zoobank.org:pub:7F675C67-1A8B-4CC3B143-653CD3EDD107.

\section{REFERENCES}

1. Bhutta, M.S., Khan, D., 1975: Digenetic trematodes of vertebrates from Pakistan. Bull. Dept. Zool. Univ. Punjab, 8, 1-175.

2. Chai, J.Y., Lee, S.H., 2002: Food borne intestinal trematode infections in the republic of Korea. Parasitol. Int., 51, 129-154.

3. Channa, M. A., Khan, M. M., Shaikh, A. A., Dharejo, A. M., 2009: Echinochasmu sjamshorensi, new species (Trematoda: Echinostomatidae) from Pond Heron, Ardeolagrayii (Aves: Ardeidae) of Jamshoro, Sindh, Pakistan. Proc. Parasitol., 48, 151-158.

4. Choi, S., Lee, D., Park, H., Oh, M., Jeon, H. K., Lee, Y., Eom, K. S., 2014: Three Echinostome species from wild birds in the Republic of Korea. Korean J. Parasitol., 52, 513-520.

5. Choi, M. H., Kim, S. H., Chung, J. H., Jang, H. Y., Joon, H. E., Chung, B.S., 2006: Morphological observations of Echinochasmus japonicas cercariae and the in vitro maintenance of its life cycle from cercariae to adults. J. Parasitol., 92, 236-241.

6. Detwiler, J.T., Zajac, A. M., Minchella, D. J., Belden, L. K., 2012: Revealing cryptic parasite diversity in a definitive host: echinostomes in muskrats. J. Parasitol., 98, 1148-1155.

7. Dharejo, A.M., Bilqees, F.M., Khan, M.M., 2007: Echinochasmus mohiuddini, new species (Trematoda: Echinosto- matidae) from Paddy Bird Ardeolagrayii (Ardeidae) of Hyderabad, Sindh, Pakistan. Proc. Parasitol., 39, 285-288.

8. Dharejo, A.M., Birmani, N.A., Khan, M.M., 2010: Echinochsmus passeri, new species (Digenea: Echinostomatidae) from gallbladder of House Sparrow, Passer domesticus (Aves: Passeridae) of Hyderabad, Sindh, Pakistan. Proc. Parasitol., 50, 139-145.

9. Dimitrov, V., Kanev, I., Bezprozvanich, V., Radev, V., 1998: Argentophilic structures of the miracidium of Echinochasmus perfoliatus (Trematoda: Echinosmatidae). Parasite, 5, 185-188.

10. Faltynková, A., Gibson, D. I., Kostadinova, A., 2008: A revision of Petasiger Dietz, 1909 (Digenea: Echinostomatidae) and a key to its species. Syst. Parasitol., 71, 1-40.

11. Gibson, D. I., Jones, A., Bray, R. A., 2005: Keys to the Trematoda, Vol. 2., CABI Publishing and the Natural History Museum, Wallingford and London, UK, 745 pp.

12. Kostadinova, A., Jones, A., 2005: Superfamily Echinostomatoidea. In Jones, A., Bray, R. A., Gibson, D. I.: Keys to the Trematoda, Vol. 2., CABI Publishing and the Natural History Museum, Wallingford and London, UK, 5-8.

13. Kudlai, O., Kostadinova., A, Pulis, E. E., Tkach, V. V., 2015: A new species of Drepanocephalus Dietz, 1909 (Digenea: Echinostomatidae) from the Double-crested Cormorant Phalacrocoraxauritus (Lesson) (Aves: Phalacrocoracidae) in North America. Syst. Parasitol., 90, 221-230.

14. Argumedo, R. L., Macedo, L. A., 1991: Trematodos de aves IV. Estudio de Echinochasmus zubeddakhanamae (Trematoda: Echinostomatidae) recuperados experimentalmente. Annales Inst. Biol. Univ. Nac. Auton. Mex. Ser. Zool., 62, 11-14.

15. Leles, D., Cascardo, P., dos Santos Freire, A., Maldonado, A., Sianto, L., Araujo, A., 2014: Insights about echinostomiasis by paleomolecular diagnosis. Parasitol. Int., 63, 646-649.

16. Overstreet, R.M., Cook, J.O., Heard, R. W., 2009: Trematoda (platyhelminthes) of the Gulf of Mexico. In Felder, D. L., Camp, D. K.: Gulf of Mexico-Origins, Waters and Biota Biodiversity. Texas A and M University Press, College station, Texas, 419-486.

17. Platt, T. R., 2006: First report of Echinochasmus sp. from the snapping turtle (Chelydraserpentina L.) from Reelfoot Lake, Tennessee, USA. Comp. Parasitol., 73, 161-164.

18. Scholz, T., Ditrich, O., Vargas-Vázquez, J., 1996: Echinochasmus leopoldinae n. sp. (Trematoda: Echinostomatidae) and data on its life-cycle. Syst. Parasitol., 33, 157-165.

19. Seo, B. S., Lee, S. H., Chai, J. Y., Hong, S. J., 1985: Studies on intestinal trematodes in Korea XX. Four cases of natural hu- 
man infection by Echinochasmus japonicus. Korean J. Parasitol., 23, 214-220.

20. Supelveda, M.S., Spalding, M.G., Kinsella, J. M., Forrester, D. J., 1996: Parasitic helminthes of the Little Blue Heron, Egrettacaerulea, in Southern Florida. J. Helminthol. Soc. Wash., 63, 136-140.

21. Tkach, V. V., Kudlai, O., Kostadinova, A., 2016: Molecular phylogeny and systematics of the Echinostomatoidea Looss, 1899 (Platyhelminthes: Digenea). Int. J. Parasitol., 46, $171-185$.

22. Toledo, R., Radev, V., Kanev, I., Gardner, S., Fried, B., 2014: History of echinostomes (Trematoda). Acta Parasitol., 59, $555-567$.
23. Ujan, H.M., Birmani, N.A., Shaikh, A.M., 2014: Echinochasmus mazharuddini n. sp. (Digenea: Echinostomatidae) from the Bank Myna Acridotheres ginginianus L. (Passeriformes: Sturnidae) in Sindh province, Pakistan. J. Entomol. Zool. Stud., 2, 226-232.

24. Wojdak, J.M., Clay, L., Moore, S., Williams, T., Belden, L. K., 2013: Echinostoma trivolvis (Digenea: Echinostomatidae) second intermediate host preference matches host suitability. Parasitol. Res., 112, 799-805.

25. Yamaguti, S., 1971: Synopsis of Digenetic Trematodes of Vertebrates. Vol. II., Keigaku Publishing Co., Tokyo, Japan, 698 pp.

Received August 9, 2017

Accepted November 14, 2017 